Research article

\title{
Leukocyte numbers and function in subjects eating $n-3$ enriched foods: selective depression of natural killer cell levels
}

\author{
Violet R Mukaro ${ }^{1,3}$, Maurizio Costabile ${ }^{1,3}$, Karen J Murphy², Charles S Hii ${ }^{1,4}$, Peter R Howe ${ }^{2}$ and \\ Antonio Ferrante ${ }^{1,3,4}$
}

\begin{abstract}
1Department of Immunopathology, Children, Youth and Women's Health Service, 72 King William Road, North Adelaide SA 5006, Australia ${ }^{2}$ Nutritional Physiology Research Centre, School of Health Sciences, University of South Australia, Adelaide SA 5000, Australia ${ }^{3}$ School of Pharmaceutical and Medical Sciences, University of South Australia, Australia, Adelaide SA 5000, Australia

${ }^{4}$ Discipline of Paediatrics, University of Adelaide, 72 King William Road, North Adelaide SA 5006, Australia
\end{abstract}

Corresponding author: Antonio Ferrante, antonio.ferrante@adelaide.edu.au

Received: 25 Feb 2008 Revisions requested: 14 Mar 2008 Revisions received: 18 Mar 2008 Accepted: 14 May 2008 Published: 14 May 2008

Arthritis Research \& Therapy 2008, 10:R57 (doi:10.1186/ar2426)

This article is online at: http://arthritis-research.com/content/10/3/R57

(C) 2008 Mukaro et al.; licensee BioMed Central Ltd. This is an open access article distributed under the terms of the Creative Commons Attribution License (http://creativecommons.org/licenses/by/2.0), which permits unrestricted use, distribution, and reproduction in any medium, provided the original work is properly cited.

\begin{abstract}
Introduction While consumption of omega-3 long-chain polyunsaturated fatty acids ( $n-3$ LCPUFA) has been recommended for those at risk of inflammatory disease such as rheumatoid arthritis, the mechanism of their anti-inflammatory effect remains to be clearly defined, particularly in relation to the dose and type of $n-3$ LCPUFA. The objective of this study was to determine whether varying the levels of $n-3$ LCPUFA in erythrocyte membrane lipids, following dietary supplementation, is associated with altered numbers and function of circulating leukocytes conducive to protection against inflammation.

Methods In a double-blind and placebo-controlled study, 44 healthy subjects aged 23 to 63 years consumed either standard or $n$-3 LCPUFA-enriched versions of typical processed foods, the latter allowing a target daily consumption of 1 gram $n-3$ LCPUFA. After six months, peripheral blood leukocyte and subpopulation proportions and numbers were assessed by flow cytometry. Leukocytes were also examined for lymphoproliferation and cytokine production, neutrophil chemotaxis, chemokinesis, bactericidal, adherence and iodination activity. Erythrocytes were analyzed for fatty-acid content.
\end{abstract}

Results Erythrocyte $n$-3 LCPUFA levels were higher and absolute leukocyte and lymphocyte numbers were lower in subjects consuming $n-3$ enriched foods than in controls. There were no changes in the number of neutrophils, monocytes, $T$ cells $\left(\mathrm{CD}^{+}\right)$, T-cell subsets $\left(\mathrm{CD}^{+}, \mathrm{CD} 8^{+}\right)$and $\mathrm{B}$ cells (CD19+). However, natural killer (NK) (CD3-CD16+CD56+) cell numbers were lower in $n-3$ supplemented subjects than in controls and were inversely related to the amount of eicosapentaenoic acid or docosahexaenoic acid in erythrocytes. No significant correlations were found with respect to lymphocyte lymphoproliferation and production of IFN- $\gamma$ and IL2 , but lymphotoxin production was higher with greater $n-3$ LCPUFA membrane content. Similarly, neutrophil chemotaxis, chemokinesis, bactericidal activity and adherence did not vary with changes in erythrocyte $n$-3 LCPUFA levels, but the iodination reaction was reduced with higher $n$-3 LCPUFA content.

Conclusion The data show that regular long-term consumption of $n-3$ enriched foods leads to lower numbers of NK cells and neutrophil iodination activity but higher lymphotoxin production by lymphocytes. These changes are consistent with decreased inflammatory reaction and tissue damage seen in patients with inflammatory disorders receiving $n$-3 LCPUFA supplementation.

\section{Introduction}

There is evidence from both experimental models and clinical studies that long-chain omega-3 polyunsaturated fatty acids ( $n$-3 LCPUFA) are beneficial in the treatment of autoimmune and allergic inflammatory conditions [1-4]. Counterbalancing $n-6$ fatty-acid intake with $n-3$ fatty acids is important because $n-6$ fatty acids, such as arachidonic acid (AA) are released during cellular activation and inflammation and metabolized to generate highly inflammatory metabolites such as the 4-series leukotrienes and 2-series prostaglandins [5-7]. Increasing the 
amounts of eicosapentaenoic acid (EPA) in membrane phospholipids not only reduces the level of $A A$ available for metabolism by the lipoxygenases and cyclooxygenases, but EPA also competes against $A A$ for metabolism to form metabolites of the 5-series leukotrienes and 3-series prostaglandins, which are significantly less pro-inflammatory than the AAderived metabolites, thereby taming the inflammatory reaction [4].

The effects of $n$-3 LCPUFA supplementation on inflammation and immune responses have been extensively studied [8]. This includes the benefits in treating patients with rheumatoid arthritis (RA), Crohn's disease, ulcerative colitis, systemic lupus erythematosus, psoriasis, atherosclerosis and asthma [9]. Despite the finding of such beneficial effects there is still insufficient evidence to enable specific recommendations to be made on the use of $n-3$ fats in these disorders [10]. These include knowledge of efficacious doses of $n$ - 3 fatty acids and the type of $n-3$ fat that is most effective. The evidence indicates that EPA and docosahexaenoic acid (DHA) have differential effects which may be further complicated by the array of immune cells and pathways which can be altered by these PUFAs [5]. This would explain the variation from study to study in the degree of benefit attained for different conditions.

Here we examine the effects of providing low-dose long-term $n-3$ fatty acids in foods on a number of parameters of innate and adaptive immune response. We also took this opportunity to explore the relationship between membrane fatty-acid composition and several components of the immune system relevant to inflammatory diseases such as RA by analyzing leukocyte levels and functional responses in blood samples obtained from subjects receiving $n$-3 LCPUFA supplementation in a 6-month intervention trial. The results showed that a higher level of $n$-3 LCPUFA in erythrocyte membrane phospholipids is associated primarily with a significantly lower number of circulating natural killer (NK) cells, which could be considered beneficial in reducing tissue damage in chronic inflammatory diseases.

\section{Materials and methods}

Ficoll 400 was obtained from Pharmacia Biotech (Uppsala, Sweden). RPMI 1640 medium and glutamine were obtained from JRH Biosciences (Lenexa, KA). Sodium diatrizoate, DMSO, N-formyl-methionyl-L-leucyl-L-phenyalanine (fMLP), Rose Bengal stain $(0.25 \% \mathrm{w} / \mathrm{v}$ in phosphate-buffered saline (PBS) with $\mathrm{Ca}^{2+}, \mathrm{Mg}^{2+}$ ), zymosan and 3,3',5,5'-tetramethylbenzidine were purchased from Sigma (St Louis, MO). Angiograffin was obtained from Schering (Leverkusen, Germany). Agarose was purchased from Calbiochem (La Jolla, CA). Tumor necrosis factor (TNF) was obtained from the Ernst-Boehringer Ingelheim Institut (Vienna, Austria). The Staphylococcus aureus strain NCTC 6571, for measuring neutrophil bactericidal activity, was obtained from the National Centre for Tissue Cultures (Oxford, UK). 125I in the form of $\mathrm{Nal}$ and
$\left[\mathrm{H}^{3}\right]$ thymidine was purchased from Amersham International (Little Chalfont, UK). All monoclonal antibodies for the determination of lymphocyte subsets, IgG1 isotype control antibody and Simultest IMK kit were obtained from BD Biosciences (San Jose, CA). Phytohemagglutinin (PHA) was obtained from Murex Diagnostics (Dartford, UK). Anti-human interferon- $\gamma$ (IFN $\gamma$ ) coating monoclonal antibody and anti-human interleukin-2 (IL-2) polyclonal antibody were purchased from Endogen (Rockford, IL). The biotin-labeled anti-human IFN $\gamma$ and anti-human IL-2-detecting monoclonal antibodies, horseradish peroxidase, streptavidin and quality-control sample for IFN $\gamma$ were also purchased from Endogen. The anti-human lymphotoxin (LT) coating and biotin-labeled anti-human LT-detecting monoclonal antibodies were purchased from R\&D Systems (Minneapolis, MN). The quality-control samples for LT and IL-2 and standards for IFN $\gamma$ were obtained from the National Institute for Biological Standards and Control (South Mimms, UK). The standards for LT were purchased from Biosource International (Camarillo, CA). The standards for IL-2 were purchased from Hazelton Biotechnologies (Vienna, Austria).

\section{Study foods}

A range of study foods including pancake mix, bread, milk, margarine, eggs, chocolate, soup mix, dips, instant oats, cheese spread, muffin mix, biscuits and salad dressing were provided by Goodman Fielder (Sydney, Australia). Foods were either enriched with $n$-3 LCPUFA from microencapsulated cod liver oil (Maritex, Aarhus, Denmark) ( $n$-3 supplemented) or were devoid of $n$-3 LCPUFA (placebo). The fatty-acid composition of the study foods is described elsewhere [10,11]. Each enriched food portion provided $125 \mathrm{mg}$ EPA + DHA and subjects were asked to consume eight exchanges daily, to equal $1 \mathrm{~g} n$-3 PUFA/day. Subjects were matched for gender and age then randomly allocated to treatment or control groups. Dietary interviews were conducted by trained dieticians using diet questionnaires and food records as described by Patch et al. [10] to score the acceptability and palatability of individual food items to ensure compliance with test foods. Subjects were encouraged to keep 'diet diaries' in order to monitor the amount of $n$-3 PUFA-rich foods consumed. The target macronutrients intakes (\% of energy) were as follows: $20 \%$ protein, $50 \%$ carbohydrate, $30 \%$ fat (polyunsaturated: mono-unsaturated: saturated $=1: 1: 1)[11]$.

\section{Subjects and study design}

A double-blind, placebo-controlled dietary intervention study of 6 months duration was approved by the Human Research Ethics Committees of the University of Adelaide and the Commonwealth Scientific and Industrial Research Organization (CSIRO) (see Murphy et al. [11] for details). The trial commenced in 2003 and consent from the subjects recruited was obtained. Forty-four non-smoking volunteers aged 20 to 65 years, who were overweight $\left(\mathrm{BMI}>25 \mathrm{~kg} / \mathrm{m}^{2}\right)$ and had fasting plasma triacylglycerol $>1.6 \mathrm{mmol} / \mathrm{l}$, but were otherwise 
healthy, were recruited from the general community through media advertisements. Volunteers were excluded if they were taking non-steroidal anti-inflammatories, antihypertensives, lipid-lowering or other drugs affecting lipid metabolism. Other exclusion criteria include the consumption of more than one fish meal per week, regularly taking fish oil supplements, inability to consume test foods, recent (previous 3 months) diagnosis of diabetes, symptomatic heart disease, angina pectoris, history of myocardial infarction or stroke, peripheral vascular disease, liver or renal disease (plasma creatinine $>120 \mathrm{mmol} /$ I), major surgery, blood pressure (BP) $>170 / 100 \mathrm{mmHg}$; or smokers and/or ex-smokers within the past two years.

\section{Erythrocyte membrane fatty-acid composition}

The fatty-acid composition was analyzed at 6 months as described by Murphy et al. [11]. Erythrocytes were isolated, lysed and the membrane lipids extracted into methanol: toluene ( $4: 1$, by volume) according to the method of Lepage and Roy [12]. Fatty-acid methyl esters were analyzed by flame-ionization gas chromatography (model GC-20A, Shimazdu Corporation, Kyoto, Japan) using a 50-m BPX70 capillary column (0.32 mm internal diameter and $0.25 \mu \mathrm{m}$ film thickness (Scientific Glass Engineering, Melbourne, Australia). Individual fatty acids were identified by comparison with known fatty-acid standards (Nuchek Prep, Elysian, MN) and expressed as a percentage of total fatty acids quantified from peak areas.

\section{Preparation of peripheral blood mononuclear cells and neutrophils}

At the end of the 6-month trial, $10 \mathrm{ml}$ blood was collected by venepuncture after a 12-h overnight fast into lithium heparin tubes. Mononuclear cells (MNL) and neutrophils were purified by the rapid one-step procedure according to Ferrante and Thong [13]. Briefly, heparinized blood was layered onto a density separation medium consisting of Ficoll 400-Hypaque, density 1.114. Following centrifugation at $600 \mathrm{~g}$ for $35 \mathrm{~min}$, the MNL and neutrophil bands were harvested and washed twice with RPMl 1640 medium by centrifugation ( 5 min $\times 600$ g) and MNL resuspension in RPMI 1640 medium or neutrophils in Hanks Buffered Salt Solution (HBSS).

\section{Neutrophil chemotaxis and chemokinesis}

Neutrophils, $5 \mu \mathrm{l}$ of $4 \times 10^{7} \mathrm{cell} / \mathrm{s} / \mathrm{ml}$, were allowed to migrate under agarose for $90 \mathrm{~min}$ at $37^{\circ} \mathrm{C} / 5 \% \mathrm{CO}_{2}$-air incubator as previously described [14] in the presence of a chemotactic gradient generated by $5 \mu \mathrm{l} 10^{-7} \mathrm{M}$ of AMLP, or $5 \mu$ of diluent DMSO ( $1 \% \mathrm{v} / \mathrm{v}$ in PBS). The distance migrated by the cells was expressed in $\mathrm{mm} / 90 \mathrm{~min}$. For chemokinesis, neutrophils $\left(20 \mu \mathrm{l} ; 4 \times 10^{7} / \mathrm{ml}\right)$ were pre-incubated with $20 \mu \mathrm{l}$ fMLP for 5 min at $37^{\circ} \mathrm{C}$ in a humidified $\mathrm{CO}_{2}\left(5 \% \mathrm{CO}_{2}\right.$ in air) incubator, centrifuged in a microcentrifuge (30 sec $\times 1 \mathrm{~g}$ force), the supernatant was removed and the cells resuspended in $20 \mu \mathrm{l}$ HBSS with phenol. The random migration in four directions top, bottom, left and right - was measured using an inverted
Leitz microscope. Chemokinesis was expressed as the mean of the distance (in millimeters) traveled in the four directions.

\section{Neutrophil adherence}

Neutrophil adherence was assayed by measuring neutrophil adherence to plasma-coated plastic surfaces [15]. To the 96well microtiter plates was added $250 \mu \mathrm{l} /$ well of $10 \%$ autologous plasma and the plates were incubated for $30 \mathrm{~min} 37^{\circ} \mathrm{C}$ in a humidified $\mathrm{CO}_{2}\left(5 \% \mathrm{CO}_{2}\right.$ in air) incubator. The plates were subsequently washed with HBSS and air-dried. Then, $100 \mu \mathrm{l}$ of $5 \times 10^{6}$ neutrophils treated with either TNF or with HBSS as a control were loaded into the wells and incubated for 30 min at $37^{\circ} \mathrm{C}$ in a $\mathrm{CO}_{2}$ incubator. Non-adherent cells were removed by inversion of plates and the wells washed three times with HBSS. Adherent cells were stained with Rose Bengal $\left(0.25 \% \mathrm{w} / \mathrm{v}\right.$ in PBS with $\left.\mathrm{Ca}^{2+}, \mathrm{Mg}^{2+}\right)$ [14], washed and the dye was then released by adding $50 \%$ ethanol and the absorbance was read at $570 \mathrm{~nm}$ using a plate reader (Dynatech MR7000, Dynatech Laboratories, Chantilly, VA). The degree of adherence was calculated by subtracting the mean absorbance values of blank wells from the mean of the test wells.

\section{Neutrophil bactericidal activity}

The ability of neutrophils to kill Staphylococcus aureus was assessed as described previously [16]. Neutrophils $\left(1 \times 10^{6}\right.$ cells) were mixed with $1 \times 10^{6} \mathrm{~S}$. aureus in HBSS and $10 \%$ (final) pooled human $A B$ serum in tubes which were then gassed with $5 \% \mathrm{CO}_{2}$-air mixture and incubated with end-toend mixing at $37^{\circ} \mathrm{C}$. Samples were taken at 0,1 and $2 \mathrm{~h}$, diluted in sterile distilled water and plated onto blood agar for colony growth and enumeration of the number of surviving bacteria.

\section{Neutrophil iodination reaction}

The quantitative neutrophil iodination reaction, which examines the ability to produce oxygen radicals and the release of myeloperoxidase enzyme, was determined by the method described by Thong and Ferrante [17]. Briefly, $25 \mu \mathrm{l}$ of $125 \mathrm{I}$ $(200 \mu \mathrm{Ci} / \mathrm{ml})$ was added to $1 \mathrm{ml}$ pooled human serum (1:4 dilution in HBSS) and $25 \mathrm{ml}$ added to appropriate wells in a 96-well microtiter plate. Six wells were used for either pooled serum or autologous serum, three of which were stimulated with $50 \mu \mathrm{l}$ zymosan. As a control, $50 \mu \mathrm{l}$ of HBSS was added to the remaining three. The plates were incubated for $30 \mathrm{~min}$ at $37^{\circ} \mathrm{C}$ in a humidified $\mathrm{CO}_{2}\left(5 \% \mathrm{CO}_{2}\right.$ in air) and then $50 \mu \mathrm{l}$ of $1 \times 10^{7}$ neutrophils $/ \mathrm{ml}$ were added to appropriate wells. The plates were covered and incubated for $90 \mathrm{~min}$. Finally, the cells were harvested using a cell harvester (Titertek Cell Harvester 550 ) and the quantity of bound ${ }^{125}$ I was expressed as picomoles $/ 10^{7}$ neutrophils. The amount of iodination due to stimulation was calculated by subtracting the basal iodination value (no zymosan added) from the stimulated iodination value (plus zymosan). 


\section{Lymphocyte phenotyping and leukocyte numbers}

Lymphocyte subpopulations were determined using a lymphocyte kit and direct two-color immunofluorescence. The kit allows for determination of all T cells $\left(\mathrm{CD}^{+} / \mathrm{CD}^{+}{ }^{+}\right.$and $\mathrm{CD} 3^{+} /$ $\left.\mathrm{CD}^{+}\right)$, monocytes $\left(\mathrm{CD} 16^{+}\right)$, NK cells (CD3/CD16+/56+) and $B$ lymphocytes $\left(C D 19^{+}\right)$in one sample simultaneously. One hundred microliters of whole-blood samples were mixed with $2 \mathrm{ml}$ of $1 \times$ lysing solution, vortexed and incubated for $10 \mathrm{~min}$ at room temperature in the dark. Immediately after incubation the tubes were centrifuged for $5 \mathrm{~min}$ at $300 \mathrm{~g}$, the supernatant was removed and the pellet resuspended in $2 \mathrm{ml}$ Isoton II. The cells were then centrifuged ( $300 \mathrm{~g} \times 5 \mathrm{~min}$ ), the supernatant was removed and the pellet fixed in formaldehyde $(200 \mu \mathrm{l} 1 \%$ solution). The fluorescence intensity was measured using a flow cytometer (FACScan, BD Biosciences, NSW, Australia). The data was processed with Lysis II software (BD Biosciences). To determine leukocyte and lymphocyte numbers, $130 \mu$ of whole blood was aspirated and analyzed using a hematology analyzer CELL-DYN 3500SL (Abbott Diagnostics, North Chicago, IL).

\section{Measurement of lymphoproliferation}

Mononuclear cells in samples of $100 \mu \mathrm{l}\left(2 \times 10^{5}\right.$ cells $)$ were cultured in medium supplemented with $4 \mathrm{mM}$ L-glutamine solution, $100 \mathrm{U} / \mathrm{ml}$ penicillin, $100 \mu \mathrm{g} / \mathrm{ml}$ streptomycin, 5\% human heat-inactivated $A B$ serum and $100 \mu \mathrm{l} \mathrm{PHA}(2 \mu \mathrm{g} / \mathrm{ml})$. The final volume of the culture was $200 \mu \mathrm{l}$, and all cultures were performed in triplicate as described previously [18]. Proliferation was measured as the incorporation of $\left[{ }^{3} \mathrm{H}\right]$ thymidine over the final $6 \mathrm{~h}$ of a 72 -h culture period.

\section{Measurement of cytokine production}

Mononuclear cells were cultured in concentrations and conditions as described above, the culture medium was removed after $72 \mathrm{~h}$ and stored at $-70^{\circ} \mathrm{C}$ for cytokine (LT, IL-2 and IFN $\gamma$ ) analysis by enzyme-linked immunosorbent assay [18].

\section{Statistical analysis}

All statistical analyses were performed using GraphPad InStat software. Data were analyzed as comparisons between placebo and $n$-3 PUFA-supplemented groups, as well as correlations between the membrane fatty-acid levels and specific immunological parameters. The Kolmogorov-Smirnov test was used to determine normal distribution of data. Linear regression analyses were performed and statistical comparisons were carried out using Student's two-tailed $t$-test for paired or unpaired data and $p<0.05$ was considered significant.

\section{Results}

\section{Erythrocyte membrane fatty-acid composition}

A total of 42 (21 placebo and 21 supplemented) individuals completed the study; however, a few samples were not viable and/or were lost, thus accounting for the variation in sample numbers. Analysis of the erythrocyte membrane lipid composition ( $n=18$ placebo and $n=20 n-3$ LCPUFA supplemented)
Figure 1
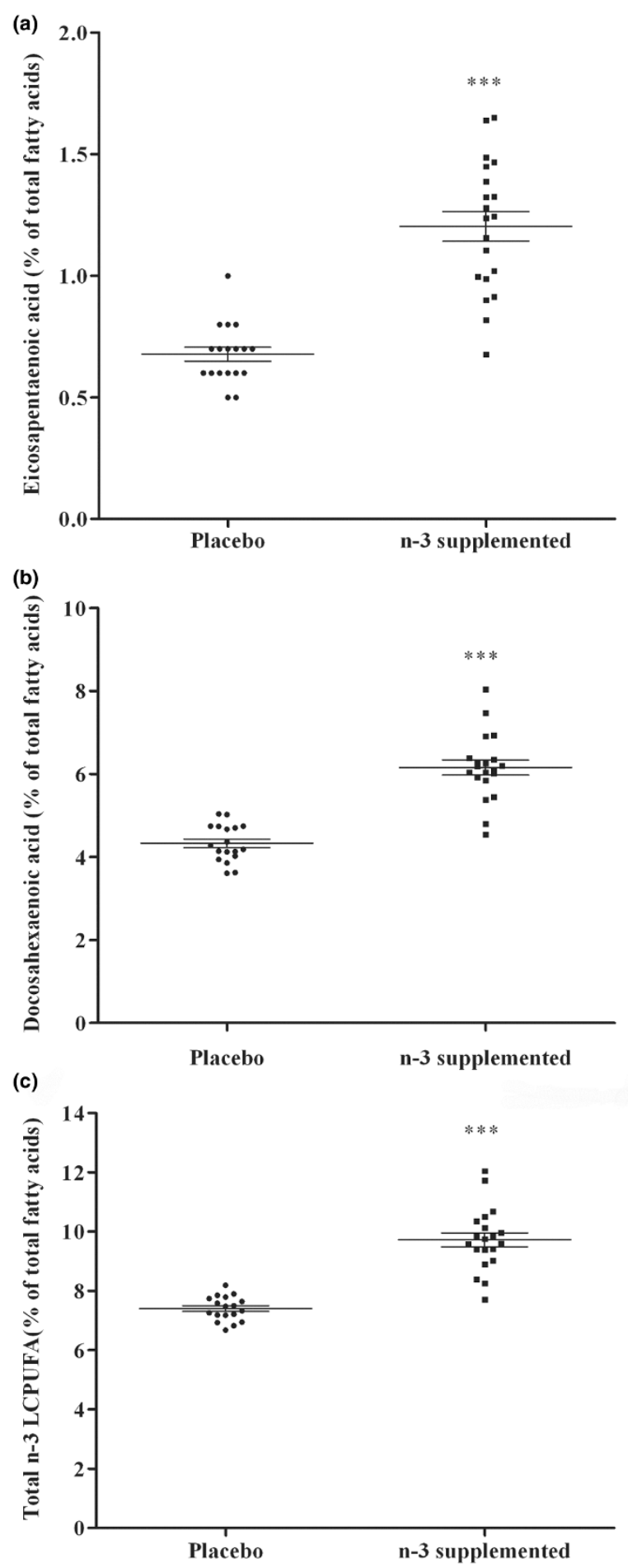

Levels of $n-3$ fatty acids in membrane phospholipids of erythrocytes. (a) Eicosapentaeonic acid (EPA), (b) docosahexaenoic aid (DHA) and (c) $n-3$ LCPUFA (EPA + docosapentaenoic acid (DPA) + DHA) in the placebo and supplemented groups. Blood was taken after 6 months and analyzed for fatty-acid composition as outlined in Materials and methods. Data are expressed as mean $\pm \mathrm{SEM} ; n=18$ for the placebo group and $n=20$ for the supplemented group. ${ }^{\star \star \star} p<0.0001$, Student $t$-test. 
showed considerable overlap in levels of $n-3$ and $n-6$ PUFA, EPA and DHA between the two groups (Figure 1). The EPA, DHA and total $n-3$ LCPUFA (docosapentaenoic acid (DPA) + $E P A+D H A)$ content in the enriched group was significantly higher than in the placebo group (Figure 1), whereas the total $n-6$ LCPUFA content was higher in the placebo group than in the supplemented groups (data not shown) $24.8 \pm 0.23 \%$ and $22.65 \pm 0.31 \%$ respectively $(p<0.0001)$.

\section{Alteration in leukocyte levels}

Total leukocyte levels were significantly lower in n-3-supplemented subjects than in controls (Figure 2a). This difference was reflected in total lymphocytes (Figure $2 b$ ). Linear regression for lymphocyte numbers versus percentage of plasma membrane fatty acid showed a significant negative correlation with EPA levels (Table 1). The correlation with DHA and total $n$-3 LCPUFA, though not significant, showed the same trend of decreasing lymphocyte numbers with higher membrane $n-3$ LCPUFA content.

Comparing the data between the $n$-3 LCPUFA supplemented and the placebo group with respect to levels of other leukocyte subpopulations showed that there was no significant difference in $\mathrm{CD}^{+}, \mathrm{CD}^{+}, \mathrm{CD}^{+}$, and CD19+ cells (Table 2). Similarly there was no significant negative correlation between the amount of membrane $n-3$ LCPUFA, EPA and DHA in erythrocytes and the levels of these leukocyte subpopulations (Table 1). However, the number of NK cells was significantly lower with $n$-3 LCPUFA supplementation (Figure 2c). Regression analysis showed a significant negative correlation between the number of $\mathrm{CD} 16^{+} / \mathrm{CD} 56^{+}$cells and amounts of EPA, DHA and total $n-3$ LCPUFA (Figure 3). The data show that with higher $n$-3 PUFA content there are fewer NK cells. In comparison, when NK cells were correlated with the total amount of $n-6$ PUFA, which decreased in the supplemented group compared with the placebo, as demonstrated above, there was a positive correlation $(r=0.34 ; p<0.05)$, higher amounts of total $n-6$ PUFA were associated with higher NKcell levels (data not shown).

\section{Lymphocyte function}

There was no difference in the PHA-induced lymphocyte proliferation in MNL from the $n$-3 LCPUFA-supplemented and placebo groups (Table 3). However, when relating the proliferation response to the levels of $n$-3 LCPUFA in the plasma membrane lipids, we demonstrated that the relationship follows a curve (U-shaped) rather than a line (Figure 4). Thus with higher membrane $n$-3 LCPUFA levels, PHA-induced proliferation was initially lower but with further increases in $n$ 3 LCPUFA content proliferation increased.

The production of IFN $\gamma$ and IL-2 by MNL stimulated by PHA was not significantly different between the $n$-3 LCPUFA supplemented and placebo groups (Table 3). Furthermore, there was no correlation between the membrane $n-3$ LCPUFA and
Figure 2
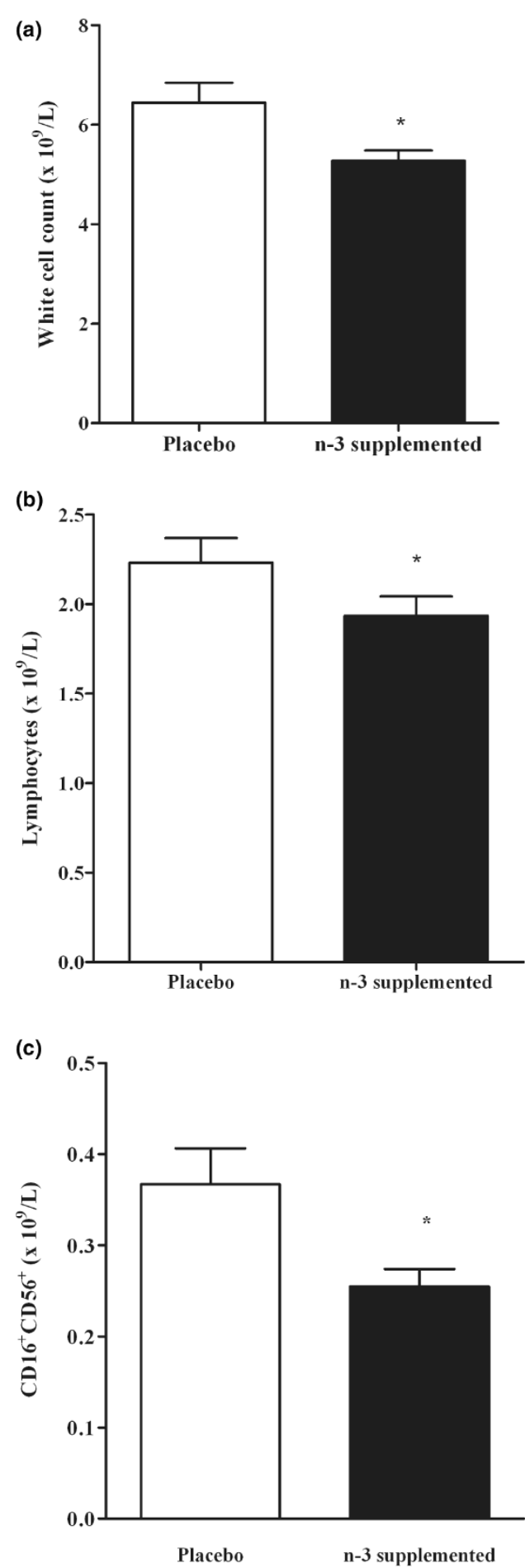

Effect of $n$-3 LCPUFA supplementation on leukocyte numbers. Number of (a) total white cells, (b) lymphocytes and (c) NK cells

$\left(\mathrm{CD} 16^{+} \mathrm{CD} 56^{+}\right)$for the placebo and $n-3$ supplemented groups. Blood was taken after 6 months and white-cell enumeration carried out as outlined in Materials and methods. Data are expressed as mean \pm SEM. ${ }^{*} p$ $<0.05$, significance of difference between placebo and supplemented (Student $t$-test). $n=19$ for both placebo and supplemented groups. 
Regression analysis of membrane $n-3$ LCPUFA content versus lymphocyte subpopulationa numbers and cytokine production

\begin{tabular}{|c|c|c|c|c|c|c|}
\hline & \multicolumn{2}{|c|}{ EPA } & \multicolumn{2}{|c|}{ DHA } & \multicolumn{2}{|c|}{$n-3$ LCPUFAc } \\
\hline & $r^{b}$ & $p$ value ${ }^{b}$ & $r$ & $p$ value & $r$ & $p$ value \\
\hline $\mathrm{CD}^{+}$ & -0.32 & 0.07 & -0.06 & 0.74 & -0.20 & 0.27 \\
\hline $\mathrm{CD}^{+}{ }^{+}$ & -0.34 & 0.06 & -0.04 & 0.84 & -0.19 & 0.28 \\
\hline $\mathrm{CD}^{+}$ & -0.17 & 0.36 & -0.07 & 0.70 & -0.12 & 0.50 \\
\hline $\mathrm{CD}^{+}: \mathrm{CD}^{+}$ & 0.14 & 0.45 & 0.01 & 0.94 & 0.06 & 0.73 \\
\hline $\mathrm{CD} 16^{+} \mathrm{CD} 56^{+}$ & $-0.39 d$ & 0.025 & -0.37 & 0.033 & -0.38 & 0.029 \\
\hline CD19+ & -0.13 & 0.47 & -0.11 & 0.56 & -0.12 & 0.50 \\
\hline $\mathrm{IFN} \gamma$ & 0.17 & 0.43 & 0.13 & 0.56 & 0.16 & 0.50 \\
\hline IL-2 & 0.23 & 0.30 & 0.23 & 0.30 & 0.26 & 0.24 \\
\hline LT & 0.43 & 0.046 & 0.18 & 0.44 & 0.27 & 0.22 \\
\hline Lymphocytes & -0.45 & 0.009 & -0.21 & 0.25 & -0.28 & 0.11 \\
\hline Neutrophils & -0.24 & 0.18 & -0.31 & 0.065 & -0.31 & 0.078 \\
\hline Monocytes & 0.06 & 0.80 & 0.41 & 0.11 & 0.28 & 0.27 \\
\hline Total leukocytes & -0.33 & 0.06 & -0.32 & 0.07 & -0.34 & 0.06 \\
\hline
\end{tabular}

${ }^{a}{ }^{C D} 3^{+}$, all circulating T cells; CD4+, all T helper cells; CD8 ${ }^{+}$, all cytotoxic T cells; CD19+, all B lymphocytes; CD16+CD56+, all NK cells; IFN $\gamma$, interferon-gamma; IL-2, interleukin 2; LT, lymphotoxin. bThe correlation coefficient $r$ value; the $p$ value shows the significance $(p<0.05)$ (ANOVA) of the obtained $r$ value. ${ }^{c} n-3$ LCPUFA refers to the sum of docosapentaenoic acid (DPA), eicosapentaenoic acid (EPA) and docosahexaenoic acid (DHA). dBoldfaced text shows results with $r$ value of $p<0.05$.

ability to produce cytokine (Table 1). In contrast, LT production by PHA-stimulated MNL was much greater in the $n$-3-supplemented group compared with placebo (Figure 5) and showed a significant and positive correlation with EPA erythrocyte content (Table 1, Figure 5).

\section{Neutrophil functions}

When comparing the neutrophil functional responses between $n$-3 LCPUFA-supplemented subjects and placebo, we found no significant differences in chemotaxis, chemokinesis, adherence and bactericidal activity (Table 4), and no significant differences between the $n$ - 3 LCPUFA levels in the erythrocyte membrane and all these functions, apart from the neutrophil iodination reaction (Table 5). The iodination response showed a 'bell-shaped' relationship when analyzed against the EPA and DHA content of erythrocyte membranes (Figure 6). This shows that there is greater iodination reaction with higher $n-3$ LCPUFA content. However, with further increases in $n$-3 LCPUFA levels, the neutrophil iodination activity was lower.

\section{Discussion}

The data showed that in association with an increase in consumption of $n$-3 LCPUFA there was a significant reduction in levels of circulating NK cells (CD16 $\left.{ }^{+} \mathrm{CD}^{+} 6^{+}\right)$. Comparisons between the supplemented and placebo group indicate that $n$ 3 LCPUFA reduces NK-cell numbers in the circulation. Analysis of the NK-cell levels against the amount of $n-3$ LCPUFA in the erythrocyte membranes established a negative correlation with the level of EPA, DHA and total $n-3$ LCPUFA. A linear correlation was seen over the $n-3$ LCPUFA range of 6.68 to $12.05 \%$. A similar correlation was seen over the EPA range of 0.48 to $1.65 \%$ and DHA of 3.61 to $8.04 \%$. The reduced NKcell numbers can only be contributing in a very small way to the reduced levels of total leukocytes and lymphocytes seen over this range of $n-3$ LCPUFA, EPA and DHA levels. While we also

Table 2

Effect of 6 months of supplementation with $n-3$ enriched foods on absolute numbers of other leukocyte subpopulations

\begin{tabular}{lcccccc}
\hline Group & CD3 & CD4 & CD8 & CD19 & Neutrophils & Monocytes \\
\hline Placebo & $1.64 \pm 0.12^{\mathrm{b}}$ & $1.05 \pm 0.09$ & $0.59 \pm 0.07$ & $0.21 \pm 0.02$ & $3.51 \pm 0.19$ & $0.25 \pm 0.03$ \\
$n-3$ supplemented & $1.47 \pm 0.09$ & $0.95 \pm 0.07$ & $0.53 \pm 0.04$ & $0.18 \pm 0.02$ & $3.04 \pm 0.13$ & $0.22 \pm 0.02$ \\
\hline
\end{tabular}

${ }^{a}$ CD3, all circulating T-cells; CD4, all T helper cells; CD8, all cytotoxic T cells; CD19, all B lymphocytes. bData are presented as cells/l ( $\left.\times 10^{9}\right)$ mean $\pm \operatorname{SEM}(n=16$ to 17$)$. 
Figure 3
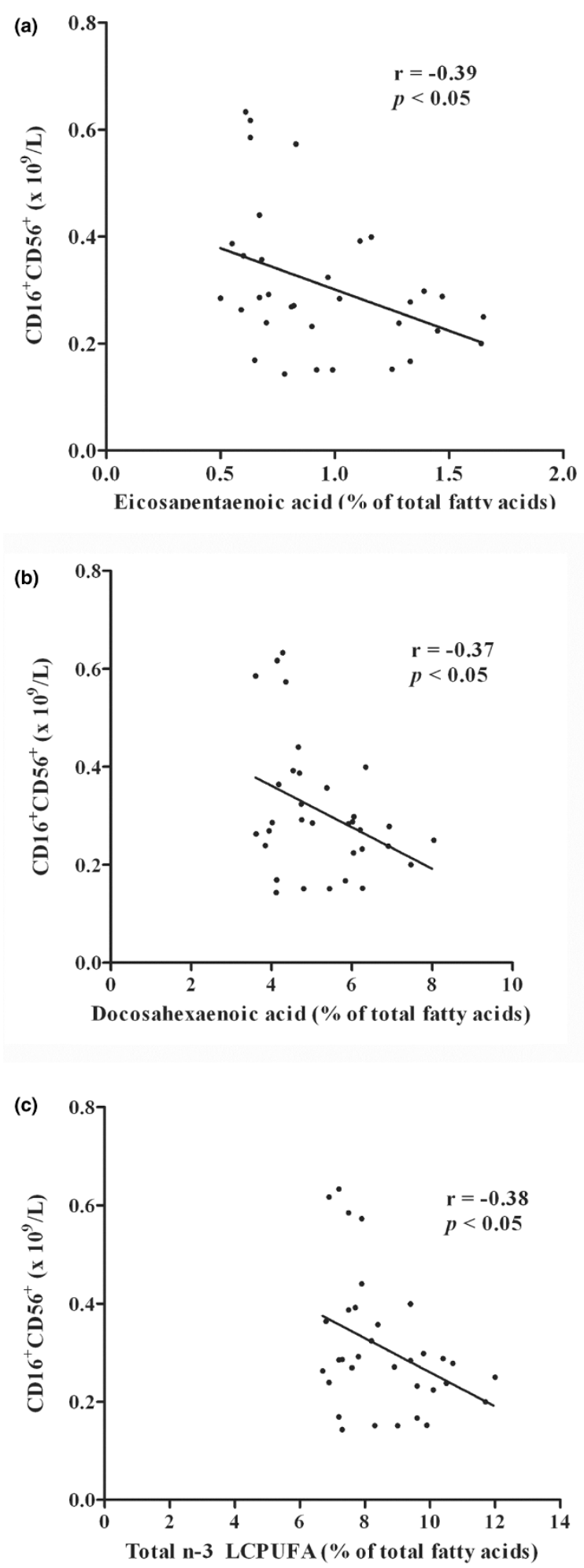

Relationship between NK-cell numbers and erythrocyte membrane lipids. (a) Eicosapentaenoic acid (EPA), (b) docosahexaenoic acid (DHA), and (c) total $n-3$ LCPUFA (EPA + DPA + DHA) after 6 months of supplementation; $n=33$. CD16 ${ }^{+} \mathrm{CD}^{2} 6^{+}$, NK cells. observed lower levels of neutrophils, T cells, B cells and T-cell subpopulations, this was not significant. This suggests that NK cells are most sensitive to increasing amounts of $n-3$ LCPUFA. Previously, others have reported that $n$-3 PUFA supplementation leads to reduced NK activity. Thies et al. [19] reported that only a moderate intake of EPA + DHA (720 mg $+280 \mathrm{mg}$ )/day (but not DHA alone), $\alpha$-linolenic (18:3n-3) or $\gamma$-linolenic acid (18:3n-6) over a 12-week period caused a reduction in NK-cell activity. No corresponding decrease in numbers or proportions of NK cells was observed. As our studies demonstrated that reduced levels are associated with greater amounts of $n-3$ LCPUFA in cell membranes, it is likely that the difference is related to the duration of the supplementation period. In fact our observations at 12 weeks of supplementation revealed that NK-cell numbers were not significantly correlated with $n$-3 LCPUFA levels in erythrocyte membranes (data not shown). Kelley et al. [20] reported a reduction in NKcell activity using $6 \mathrm{~g} \mathrm{DHA}$ /day over 12 weeks and this was also associated with an increase in DHA (2.3 to $7.4 \%$ of total fatty acids) in MNL. However, the NK-cell numbers or proportions were not measured. More recently, Miles et al. [21] reported that supplementation with $4 \mathrm{~g} /$ day of EPA had little effect on the magnitude of NK-cell activity. We now report that a major consequence of increasing cell membrane levels of $n$ 3 LCPUFA is a correlated decrease in NK-cell numbers. Collectively, the above studies suggest that under appropriate $n$ 3 PUFA enrichment, both NK-cell numbers and NK-cell activity are reduced.

While NK cells are important in immune surveillance, particularly against viral infections and cancer [22-24], the cells are also likely to play a role in the pathogenesis of inflammatory diseases as they have the ability to produce high levels of the pro-inflammatory cytokines IFN- $\gamma, \mathrm{IL}-1$ and TNF, and are cytotoxic for tissues. For example, decreased NK-cell activity has been implicated as a protective mechanism of $n-3$ LCPUFA (EPA and DHA) in patients with ulcerative colitis [25]. Aaskov et al. [26] reported that NK cells from patients with epidemic polyarthritis could lyse autologous synovial cells and hence contribute to the arthritis. The ability of $n-3$ LCPUFA to reduce circulating NK-cell numbers could be another way in which $n$ 3 LCPUFA protect against these inflammatory disorders, acting in concert with the established dogma that $n-3$ LCPUFA reduce the levels of potent pro-inflammatory eicosanoids [9]. Our findings also raise the possibility that $n-3$ LCPUFA may protect during infection-induced exacerbation of tissue damage in RA patients through an effect on NK-cell levels. Whether or not the NK cells in our studies were also less cytotoxic remains to be established, but on the basis of previous reports this is likely and would add to the anti-inflammatory effects, which our findings support. The basis for the reduced NK-cell numbers will need to be further studied. However, it is likely to be related to an effect on hematopoiesis, perhaps selectively affecting NK-cell development. 
Table 3

Effect of 6 months of supplementation with $n-3$ enriched foods on PHA-induced cytokine production and proliferation in peripheral blood mononuclear leukocytes

\begin{tabular}{llll}
\hline Group & IL-2a & IFN $\gamma^{\mathrm{a}}$ & PHA proliferation \\
\hline Placebo & $1.83 \pm 0.61$ & $39.77 \pm 12.53$ & $193800 \pm 20840$ \\
$n-3$ supplemented & $4.01 \pm 1.73$ & $57.24 \pm 11.62$ & $191100 \pm 19520$ \\
\hline
\end{tabular}

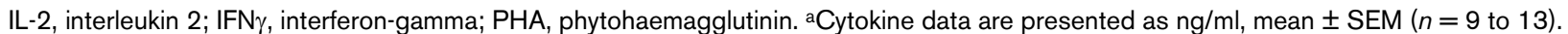

bProliferation data expressed in disintegration per minute (dpm).

Earlier studies, which examined the effects of dietary supplementation with $n-3$ LCPUFA on immune function, in most cases used daily doses as high as $5.4 \mathrm{~g}$ and, not surprisingly, demonstrated a marked suppression of immunological responses such as neutrophil chemotaxis, MNL cytokine production and lymphocyte proliferation [27-29]. Another study, which used high doses of $n$-3 LCPUFA, (14.4 g per day over 10 weeks) reported a large reduction in neutrophil chemotaxis (93\%) [27]. It is usually accepted that depressed neutrophil functions are not seen at lower doses such as those used in our study.

At these lower doses we found very little effect on lymphocyte function. There was no difference in lymphocyte proliferation to PHA between the $n$-3 LCPUFA-supplemented and placebo groups. This contrasted with the observations of the production of cytokines by $T$ cells. Whereas there was no significant difference between the two groups in the production of IL-2 and IFN $\gamma$, LT production was increased in the $n$-3 LCPUFAsupplemented group compared with placebo at 6 months. However, the PHA-induced proliferation exhibited a U-shaped relationship with the increases in $n-3$ LCPUFA content. This effect of PHA-induced proliferation was somewhat mirrored in the production of PHA-induced LT. Regression analysis showed a positive correlation between the LCPUFA levels in erythrocyte membranes and LT production by lymphocytes. The discrepancy in the pattern of regression - that is, linear in the case of LT or U-shaped in that of PHA-induced proliferation - suggests that the proliferation response is more complex in terms of sensitivity to the membrane content of fatty acids compared to the production of LT. It remains to be established why low-dose $n$-3 LCPUFA supplementation promotes production of LT but not the other T-cell cytokines, IFN $\gamma$ and IL-2. Nevertheless, such increases in LT production can be protective against tissue damage in RA. It has been demonstrated that, unlike TNF, IFN $\gamma$ and IL-2, which augment neutrophil-mediated inhibition of cartilage proteoglycan synthesis, LT markedly depressed this activity [30]. Others have shown that with increases in dose of EPA there is greater production of the anti-inflammatory cytokine IL-4 [21].

Neutrophil functions, chemotaxis, chemokinesis, adhesion and bactericidal activity were unaffected by $n-3$ LCPUFA supplementation. Our finding of bell-shaped relationships for the iodination activity may also be of importance in protection against tissue damage in RA. The iodination reaction is a measure of the production of hypochlorous acid by neutrophils through the generation of $\mathrm{H}_{2} \mathrm{O}_{2}$ and release of myeloperoxidase [31]. Interestingly this system was found to be important for articular cartilage damage by neutrophils [30].

Analyses of the relationship between membrane LCPUFA profiles and the content and immune function of peripheral blood leukocytes has been previous examined in non-supplemented subjects [32], who would be expected to have lower $n$-3 LCPUFA levels than our study subjects who received $n-3$ LCPUFA supplementation. Kew et al. [32] reported that DHA was positively correlated with neutrophil, monocyte and lymphocyte responsiveness. This relationship was maintained even with $\mathrm{AA}$, although there was a negative correlation with the $n-6: n-3$ ratio. This may be different when the higher levels attained with $n-3$ supplementation are taken into consideration. As Kew et al. [32] indicated in their studies, there might be a bell-shaped relationship between functional activity of leukocytes and LCPUFA concentration. Indeed, this was evident in the current study where $n-3$ supplementation was used. Others have reported a U-shaped correlation between doses of fish oil supplementation $(0.3,1.0$ and $2.0 \mathrm{~g} /$ day) and leukocyte function [33].

Our approach was to analyze the immune parameters against the corresponding LCPUFA level in erythrocyte membrane lipids of the individual subject. These levels can be related to supplementation doses and also serve to overcome some limitations associated with compliance and various confounding factors. It is also apparent that $n$-3 LCPUFA levels in plasma, erythrocytes and leukocytes can be correlated. Thus changes in levels of EPA and DHA in erythrocytes and leukocytes appear to correlate during $n-3$ LCPUFA supplementation $[34,35]$, although the rate of incorporation between these cell types is different in the first 6 to 12 weeks of supplementation. Leukocytes, especially neutrophils, are likely to undergo some activation or stimulation during purification and thus the fattyacid content may not be a reflection of the amount in the unactivated state, possibly explaining some of the controversies in findings by different laboratories. Thus the measurements in erythrocytes may be a more reliable marker for routine testing than those in leukocytes, although inevitably the latter are required to delineate the mechanisms involved. While future studies should consider the relationship between the cell type 
Figure 4
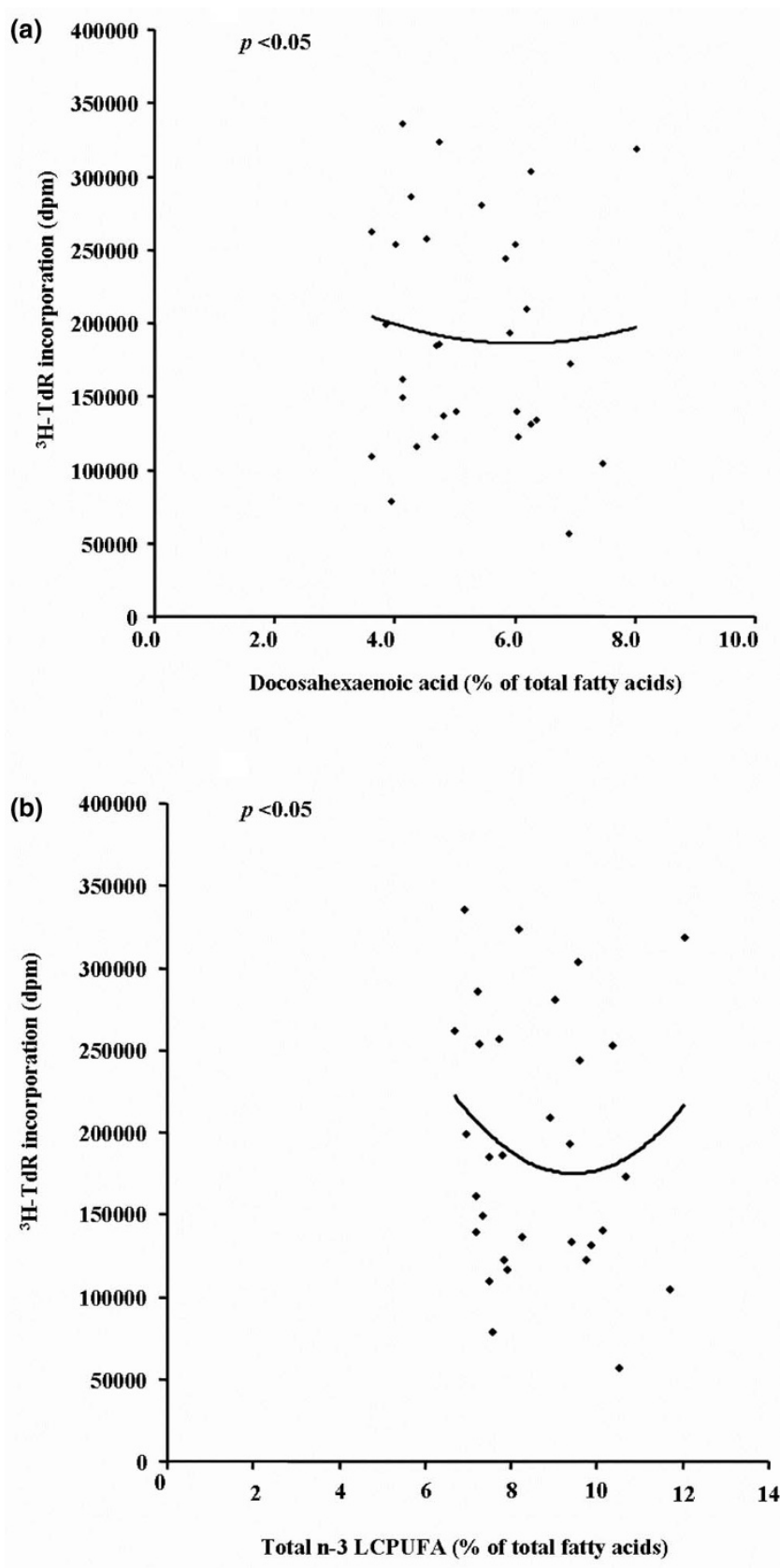

Relationship between PHA-induced proliferation in peripheral blood mononuclear cells and the $n-3$ LCPUFA content of erythrocyte membranes. Proliferation was measured by incorporation of $\left[{ }^{3} \mathrm{H}\right]$ thymidine $\left({ }^{3} \mathrm{H}-\mathrm{TdR}\right)$. There was a significant correlation between $\left[{ }^{3} \mathrm{H}\right]$ thymidine incoporation and (a) DHA and (b) total $n-3$ LCPUFA (EPA + DPA + DHA) following a curve $(p<0.05 ; n=31)$.

being examined and levels within that cell, this then becomes a complex question, as leukocytes consist of subpopulations of different cell types.

While the lower number of NK cells associated with low-dose long-term $n$-3LCPUFA supplementation is likely to be benefi-
Figure 5

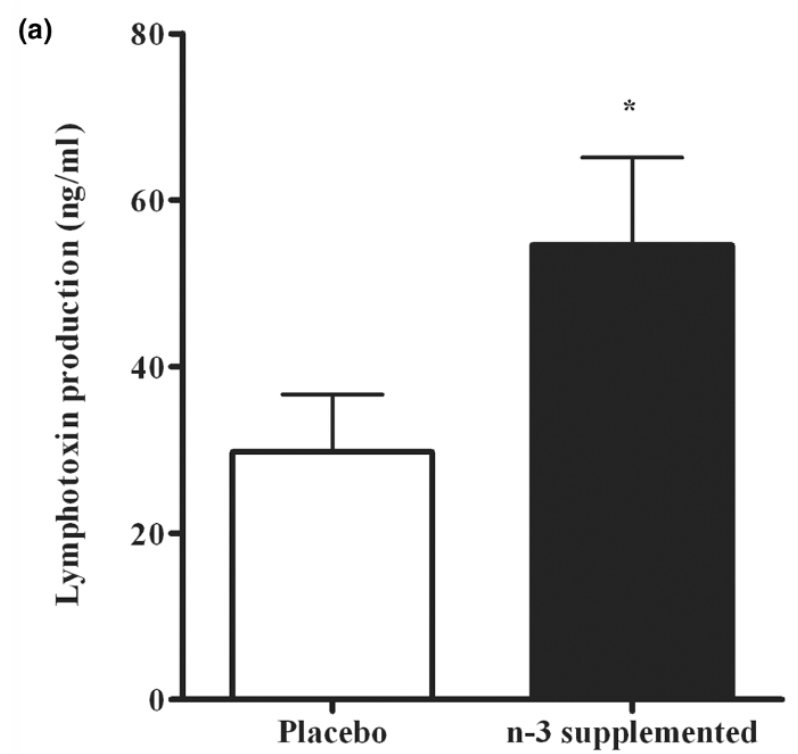

(b)

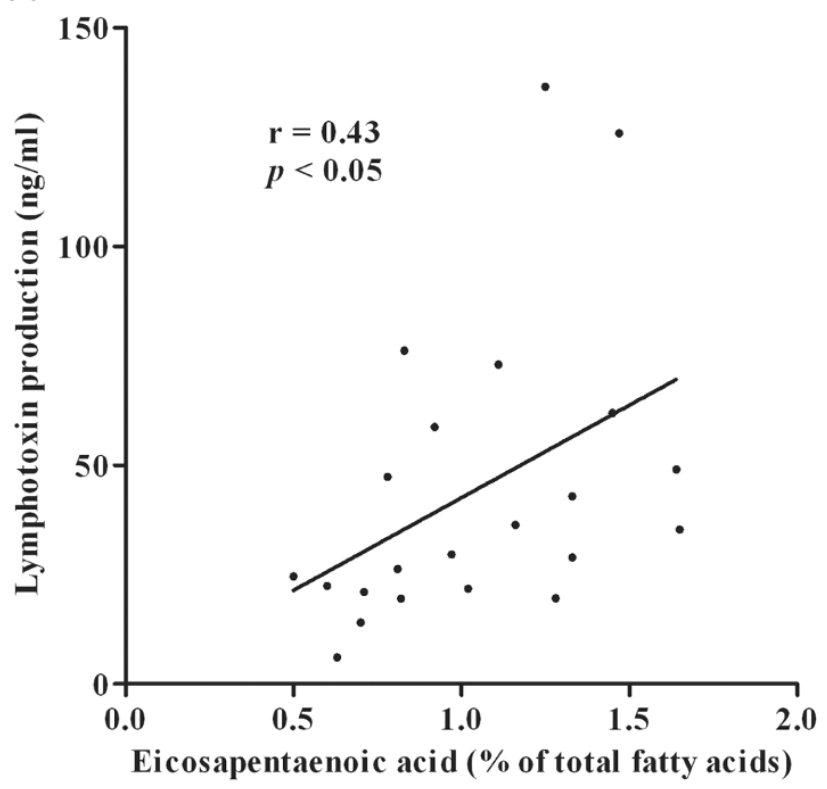

Effect of $n$-3 LCPUFA supplementation on the production of lymphotoxin (LT). (a) Peripheral blood mononuclear leukocytes were incubated with PHA and the production of LT was determined after $72 \mathrm{~h}$ incubation. ${ }^{*} p<0.05$, significance of difference between placebo and supplemented (Student $t$-test). Data are expressed as mean \pm SEM; $n=9$ for the placebo group and $n=13$ for the supplemented group. (b) Relationship between LT production and erythrocyte membrane eicosapentaenoic acid (EPA) after 6 months supplementation.

cial to patients with inflammatory disorders, it is also evident that individuals consuming these fatty acids may have greater susceptibility to viral infections. NK cells provide a first-line defense against these pathogens [36]. It is, however, reassuring that at these lower doses of supplementation, most com- 
Table 4

Effect of 6 months of supplementation with $n-3$ enriched foods on neutrophil functions

\begin{tabular}{llllll}
\hline Group & Adherence $^{\mathrm{a}}$ & Bactericidal $^{b}$ & Chemokinesis $^{c}$ & Chemotaxis $^{c}$ & lodination $^{\mathrm{d}}$ \\
\hline Placebo & $0.36 \pm 0.10$ & $95.4 \pm 0.52$ & $0.76 \pm 0.09$ & $1.94 \pm 0.092$ & $7.93 \pm 0.98$ \\
$n$-3 supplemented & $0.29 \pm 0.058$ & $97.1 \pm 0.63$ & $0.76 \pm 0.0356$ & $1.91 \pm 0.07$ & $8.03 \pm 0.65$ \\
\hline
\end{tabular}

Data are presented as mean $\pm \operatorname{SEM}(n=16$ to 17$)$. aAdherence expressed as relative absorbance at $570 \mathrm{~nm}$.

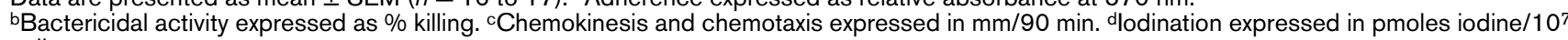
cells.

ponents of the innate and adaptive immune response were not affected over the long term.

\section{Conclusion}

The approach reported here illustrates the importance of relating immune parameters to the levels of erythrocyte membrane PUFA composition to establish a biochemical basis for endeavors to supplement people with $n$-3 LCPUFA using functional foods. It is thus tempting to suggest that such measurements could be used as indices for predictions of protection against inflammation, and as a way of controlling the level of $n-3$ LCPUFA supplementation. Furthermore, of all the immune parameters measured, NK cells were the most sensitive to the effects of increasing amounts of $n$-3 LCPUFA in the diet. This is conducive to $n-3$ LCPUFA supplementation reducing cellular inflammation and tissue damage in diseases such as RA. Future studies designed to elucidate the basis for the reduced numbers of NK cells could give us new directions for the use of $n$-3 LCPUFA supplementation.

\section{Competing interests}

The authors declare that they have no competing interests.

Table 5

Regression analysis of membrane $n-3$ LCPUFA content versus neutrophil function

\begin{tabular}{lcccccc}
\hline \multirow{2}{*}{ Function } & \multicolumn{2}{c}{ EPA } & \multicolumn{2}{c}{ DHA } & $n-3$ LCPUFA $^{\mathrm{a}}$ \\
\cline { 2 - 7 } & $r^{\mathrm{b}}$ & $p$ value $^{\mathrm{b}}$ & $r$ & $p$ value & $r$ & $p$ value \\
\hline Adherence & -0.09 & 0.73 & -0.08 & 0.77 & -0.072 & 0.79 \\
Chemotaxis & -0.11 & 0.62 & -0.12 & 0.57 & -0.12 & 0.58 \\
Chemokinesis & 0.20 & 0.38 & 0.13 & 0.55 & 0.23 & 0.30 \\
Bactericidal & 0.30 & 0.15 & 0.21 & 0.33 & 0.25 & 0.24 \\
lodination & 0.04 & 0.86 & 0.04 & 0.86 & 0.01 & 0.95 \\
\hline
\end{tabular}

an-3 LCPUFA refers to the sum of docosapentaenoic acid (DPA), eicosapentaenoic acid (EPA) and docosahexaenoic acid (DHA).

bThe correlation coefficient $r$ value; the $p$ value shows the

significance $(p<0.05)$ (ANOVA) of the obtained $r$ value.

\section{Figure 6}

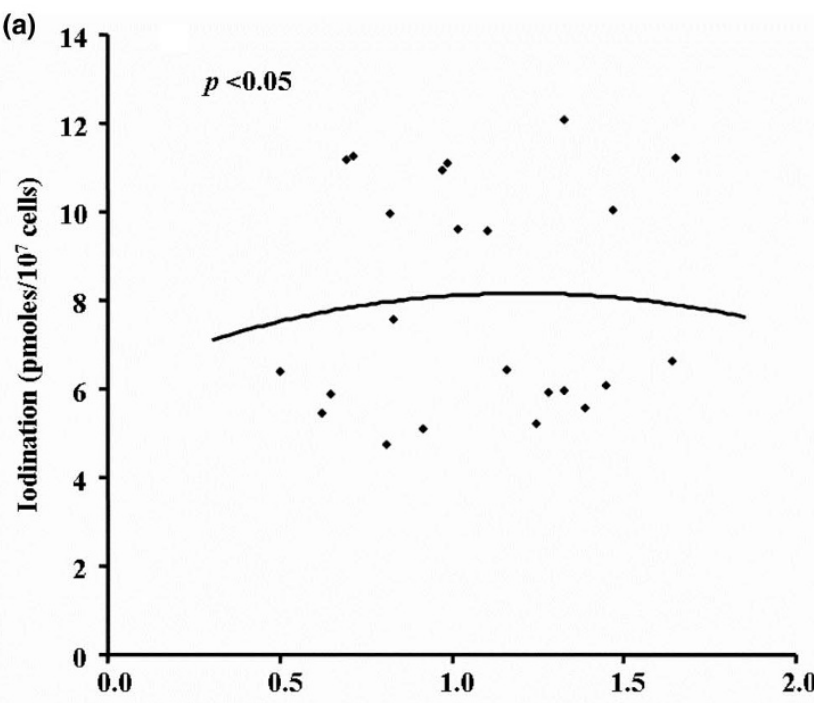

Eicosapentaenoic acid ( $\%$ of total fatty acids)

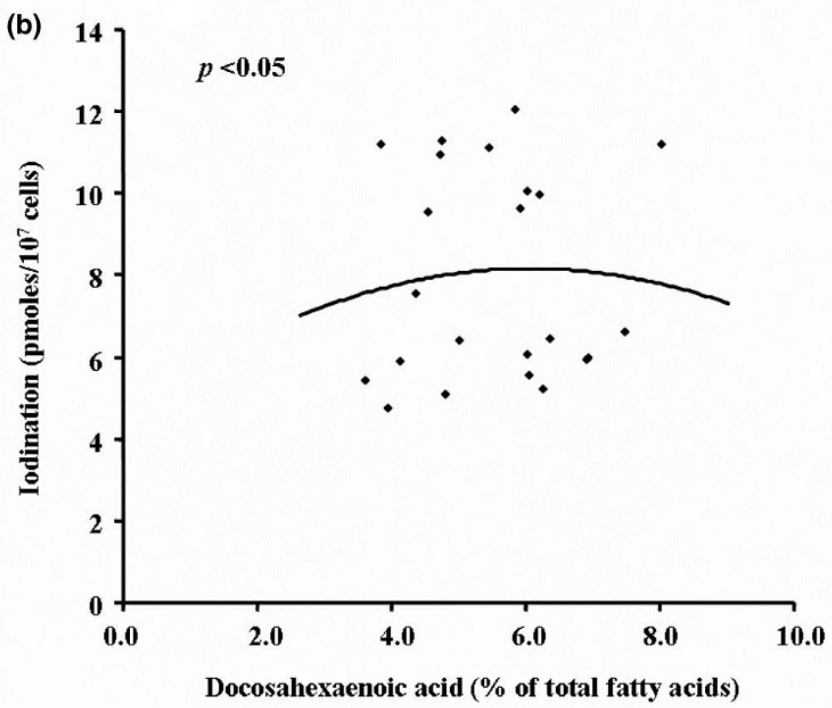

Relationship between neutrophil quantitative iodination reaction and the $n$-3 LCPUFA content of erythrocyte membranes. There was a significant correlation between the iodination activity and (a) EPA and (b) DHA following a curve $(p<0.05 ; n=23)$. 


\section{Authors' contributions}

VRM was responsible for conducting the immunology experiments; KJM was responsible for conducting the fatty-acid analyses. $\mathrm{PRH}$ and $\mathrm{KJM}$ were responsible for the organization of the subjects and diet supplements. All authors participated in study design, writing the manuscript and data analyses/ interpretation.

\section{Acknowledgements}

We are grateful to the staff of Department of Immunopathology at CYWHS for assistance with the leukocyte assays. We thank Nancy Briggs for assistance with the statistical analysis.

\section{References}

1. Kremer JM, Bigauoette J, Michalek AV, Timchalk MA, Lininger L, Rynes RI, Huyck C, Zieminski J, Bartholomew LE: Effects of manipulation of dietary fatty acids on clinical manifestations of rheumatoid arthritis. Lancet 1985, 1:184-187.

2. Donadio JV Jr, Bergstralh EJ, Offord KP, Spencer DC, Holley KE: A controlled trial of fish oil in IgA nephropathy. Mayo Nephrology Collaborative Group. N Eng/ J Med 1994, 331:1194-1199.

3. Stamp LK, James MJ, Cleland LG: Diet and rheumatoid arthritis: a review of the literature. Semin Arthritis Rheum 2005, 35:77-94

4. Calder PC: $n-3$ polyunsaturated fatty acids, inflammation, and inflammatory diseases. $A m$ J Clin Nutr 2006, 83(6 Suppl):1505S-1519S.

5. Simopoulos AP: The importance of the ratio of omega-6/ omega-3 essential fatty acids. Biomed Pharmacother 2002, 56:365-379.

6. Wu D, Meydani $S N$ : $n-3$ polyunsaturated fatty acids and immune function. Proc Nutr Soc 1998, 57:503-509.

7. James MJ, Gibson RA, Cleland LG: Dietary polyunsaturated fatty acids and inflammatory mediator production. Am J Clin Nutr 2000, 71(1 Suppl):343S-348S.

8. Simopoulos AP: Essential fatty acids in health and chronic disease. Am J Clin Nutr 1999, 70(3 Suppl):560S-569S.

9. Akabas SR, Deckelbaum RJ: Summary of a workshop on $n-3$ fatty acids: current status of recommendations and future directions. Am J Clin Nutr 2006, 83(6 Suppl):1536S-1538S.

10. Patch CS, Tapsell LC, Mori TA, Meyer BJ, Murphy KJ, Mansour J, Noakes M, Clifton PM, Puddey IB, Beilin LJ, Annison G, Howe PR: The use of novel foods enriched with long-chain $n-3$ fatty acids to increase dietary intake: a comparison of methodologies assessing nutrient intake. J Am Diet Assoc 2005, 105:1918-1926.

11. Murphy KJ, Meyer BJ, Mori TA, Burke V, Mansour J, Patch CS, Tapsell LC, Noakes M, Clifton PA, Barden A, Puddey IB, Beilin LJ, Howe PR: Impact of foods enriched with n-3 long-chain polyunsaturated fatty acids on erythrocyte $n-3$ levels and cardiovascular risk factors. Br J Nutr 2007, 97:749-757.

12. Lepage G, Roy CC: Direct transesterification of all classes of lipids in a one-step reaction. J Lipid Res 1986, 27:114-120.

13. Ferrante A, Thong YH: Separation of mononuclear and polymorphonuclear leucocytes from human blood by the one-step Hypaque-Ficoll method is dependent on blood column height. $J$ Immunol Methods 1982, 48:81-85.

14. Hii CS, Anson DS, Costabile M, Mukaro V, Dunning K, Ferrante A: Characterization of the MEK5-ERK5 module in human neutrophils and its relationship to ERK1/ERK2 in the chemotactic response. J Biol Chem 2004, 279:49825-49834.

15. Bates EJ, Ferrante A, Harvey DP, Poulos A: Polyunsaturated fatty acids increase neutrophil adherence and integrin receptor expression. J Leukoc Biol 1993, 53:420-426.

16. Ferrante A, Martin AJ, Bates EJ, Goh DH, Harvey DP, Parsons D, Rathjen DA, Russ G, Dayer JM: Killing of Staphylococcus aureus by tumor necrosis factor-alpha-activated neutrophils. The role of serum opsonins, integrin receptors, respiratory burst, and degranulation. J Immunol 1993, 151:4821-4828.

17. Thong $\mathrm{YH}$, Ferrante A: A semi-automated microassay technique for quantitative leukocyte iodination. $J$ Immunol Methods 1978, 20:297-299.
18. Costabile M, Hii CS, Melino M, Easton C, Ferrante A: The immunomodulatory effects of novel beta-oxa, beta-thia, and gamma-thia polyunsaturated fatty acids on human $T$ lymphocyte proliferation, cytokine production, and activation of protein kinase C and MAPKs. J Immunol 2005, 174:233-243.

19. Thies F, Nebe-von-Caron G, Powell JR, Yaqoob P, Newsholme EA, Calder PC: Dietary supplementation with eicosapentaenoic acid, but not with other long-chain $n-3$ or $n-6$ polyunsaturated fatty acids, decreases natural killer cell activity in healthy subjects aged $>55$ y. Am J Clin Nutr 2001, 73:539-548.

20. Kelley DS, Taylor PC, Nelson GJ, Mackey BE: Dietary docosahexaenoic acid and immunocompetence in young healthy men. Lipids 1998, 33:559-566.

21. Miles EA, Banerjee T, Wells SJ, Calder PC: Limited effect of eicosapentaenoic acid on T-lymphocyte and natural killer cell numbers and functions in healthy young males. Nutrition 2006, 22:512-519.

22. Broek MF van den, Hengartner $\mathrm{H}$ : The role of perforin in infections and tumour surveillance. Exp Physio/ 2000, 85:681-685.

23. Moretta A, Bottino C, Mingari MC, Biassoni R, Moretta L: What is a natural killer cell? Nat Immuno/ 2002, 3:6-8.

24. Diefenbach $A$, Raulet $\mathrm{DH}$ : The innate immune response to tumors and its role in the induction of T-cell immunity. Immunol Rev 2002, 188:9-21.

25. Almallah YZ, El-Tahir A, Heys SD, Richardson S, Eremin O: Distal procto-colitis and $n-3$ polyunsaturated fatty acids: the mechanism(s) of natural cytotoxicity inhibition. Eur J Clin Invest 2000, 30:58-65.

26. Aaskov JG, Dalglish DA, Harper JJ, Douglas JF, Donaldson MD, Hertzog PJ: Natural killer cells in viral arthritis. Clin Exp Immunol 1987, 68:23-32.

27. Sperling RI, Benincaso Al, Knoell CT, Larkin JK, Austen KF, Robinson DR: Dietary omega-3 polyunsaturated fatty acids inhibit phosphoinositide formation and chemotaxis in neutrophils. Clin Invest 1993, 91:651-660.

28. Lee TH, Hoover RL, Williams JD, Sperling RI, Ravalese J 3rd, Spur BW, Robinson DR, Corey EJ, Lewis RA, Austen KF: Effect of dietary enrichment with eicosapentaenoic and docosahexaenoic acids on in vitro neutrophil and monocyte leukotriene generation and neutrophil function. N Engl J Med 1985, 312:1217-1224.

29. Endres S, Ghorbani R, Kelley VE, Georgilis K, Lonnemann G, Meer JW van der, Cannon JG, Rogers TS, Klempner MS, Weber PC, et al.: The effect of dietary supplementation with $n-3$ polyunsaturated fatty acids on the synthesis of interleukin- 1 and tumor necrosis factor by mononuclear cells. N Engl J Med 1989, 320:265-271.

30. Ferrante A, Kowanko IC, Bates EJ: Mechanisms of host tissue damage by neutrophils activated by cytokines. In Immunol Ser. Volume 57. Edited by: Coffey R. New York: Marcel Dekker; 1992:499-521.

31. Ferrante A: Phagocytes Part 2: Neutrophils. In Topley and Wilson's Microbiology and Microbial Infections (Immunology) Edited by: Kaufmann SH, Steward MW. London: Hodder Arnold; 2005:35-54.

32. Kew S, Banerjee T, Minihane AM, Finnegan YE, Williams CM, Calder PC: Relation between the fatty acid composition of peripheral blood mononuclear cells and measures of immune cell function in healthy, free-living subjects aged 25-72 y. $A m \mathrm{~J}$ Clin Nutr 2003, 77:1278-1286.

33. Trebble T, Arden NK, Stroud MA, Wootton SA, Burdge GC, Miles EA, Ballinger AB, Thompson RL, Calder PC: Inhibition of tumour necrosis factor-alpha and interleukin 6 production by mononuclear cells following dietary fish-oil supplementation in healthy men and response to antioxidant co-supplementation. Br J Nutr 2003, 90:405-412.

34. Marangoni F, Angeli MT, Colli S, Eligini S, Tremoli E, Sirtori CR, Galli C: Changes of $n-3$ and $n-6$ fatty acids in plasma and circulating cells of normal subjects, after prolonged administration of 20:5 (EPA) and 22:6 (DHA) ethyl esters and prolonged washout. Biochim Biophys Acta 1993, 1210:55-62.

35. Mu H, Thogersen RL, Maaetoft-Udsen K, Straarup EM, Frokiaer H: Different kinetic in incorporation and depletion of $n-3$ fatty acids in erythrocytes and leukocytes of mice. Lipids 2006 41:749-752.

36. Lanier LL: Evolutionary struggles between NK cells and viruses. Nat Rev Immunol 2008, 8:259-268. 